\title{
Study on Household Energy Usage Patterns in Urban and Rural Areas of Nepal
}

\author{
Dinesh Kumar Shahi ${ }^{1}, *$, Hom Bahadur Rijal ${ }^{1}$, Masanori Shukuya ${ }^{1}$ \\ ${ }^{1}$ Graduate School of Environment and Information Studies, Tokyo City University, Yokohama, Japan \\ Email: shahi0608@outlook.com
}

\begin{abstract}
:
In the last decades, the household's energy demand has increased significantly in various countries including Nepal. In the case of Nepal, $94 \%$ of energy use is in the domestic sector. There is a possibility of a huge increase in electricity production, but we are still suffering from load shedding due to the high electricity demand. Electricity use is an important factor for the quality of life and development of a nation. There is not a sufficient number of researches done about electricity consumption in different climatic regions of Nepal which are analyzed by the income level of residents. This study gives descriptive information on the household's energy uses patterns and investigates the electricity use rate, using electrical appliances in households. This study also identifies the major source of energy use and awareness of energy use. The data were collected from 442 households in three regions in the winter season of 2018. Kalikot is a rural area, Chitwan is a semi-urban, and Kathmandu is an urban area. We have collected electricity bills, family income, and family size, electricity using appliances, expenditure for energy and energy use for heating/cooling, cooking, and lighting. The electricity was used only for lighting purposes in the rural area, but other electrical appliances were used in semi-urban and urban areas. The amount of electricity use has not affected by household income level in the rural area, but it has affected in semiurban and urban areas. The level of education affects the use of the LED significantly. This study would be helpful to know the electricity use patterns which is useful for energy saving and energy management of the rural and urban areas of Nepal.
\end{abstract}

Keywords: Household, Rural, Urban, Electrical Appliances, Income, Household Size, Energy Saving

\section{Introduction}

Energy is important for economic development, but it also plays a major role in improving conditions at the household level. The availability of energy sources is one of the rational basic requirements for the quality of life and development of the nation. It also one of the basic factors for the development of any civilized society and it require to upgrade the quality of lifestyle, socio-economic growth, and human development of the country. The structure of energy use in rural and urban areas has a huge impact on household income and the well-being of residents [1]. Globally, 1.06 billion people do not have access to electricity and more than 3 billion still use fuels like wood, charcoal, coal, and dung for cooking and heating [2]. The world energy use increases by $28 \%$ in the IEO 2017 reference case, with more than half of the increase, attributed to non-OECD Asia (including China and India) between 2015 and 2040. Energy use in nonOECD countries will increase by $41 \%$ between 2015 and 2040 in contrast to a $9 \%$ increase in OECD countries. Most of the increase occurs in large, emerging non-OECD countries, where the population continues to shift from rural to urban areas. Electricity use in buildings will grow $2 \%$ annually between 2015 and 2040 as rising standards of living in non-OECD countries for increasing the demand for appliances, personal equipment, and commercial services. Electricity is used for lighting, cooling, and electric appliances are the fastest-growing source of energy use in buildings between 2015 and 2040 [3].

The characteristics of households such as spatial size, number of persons, educational level, cooking habits and lifestyle, access to energy, and price of energy are affecting energy use [4-9]. There are some possible factors which are also responsible for the energy use of rural and urban areas such as different tariff, household income, family size, occupation, using different electrical appliances, housing structure, location or climate, demographic characteristics and variation in the intensity of use of electricity using devices [8-10]. The electricity demand is different in rural to urban because in rural areas people depend on fuelwood, charcoal, kerosene to meet their energy requirement, and use a small amount of electricity for lighting [11]. Biomass-based fuels are being steadily replaced with modern fossil fuels and electricity in developing countries [12]. The income level and access to the energy of households also affect the choice of energy. Income is an important factor determining the choice of fuel preferences at the household level [13]. The 
patterns of electricity use change when there is a change in income level [14]. In developing countries, access and use of energy are essential to reduce poverty. The household's choice of cleaner fuels for lighting, cooking, and heating is driven by the level of income, age, education, and gender of household, access to electricity, and location. Households with a better-education, those with a higher level of income, and urban households, have a higher probability of using clean energy, while poor households and those with a low level of education are constrained by these factors to continue using traditional energy [15].

Nepal is one of the least developed countries with $81 \%$ of its household residing in rural areas. Access to clean energy is not so good in rural areas, but it is well accessible in urban areas. The households account for nearly $87 \%$ of the total final energy in Nepal [16]. The poor energy access in Nepal hardly improves the basic human needs and this situation will be improved by little in the Next 30 years [17]. In Nepal, around 302.4 PJ $(80.36 \%)$ out of $376.3 \mathrm{PJ}$ is used for the residential sector. The demand for energy is increasing day by day because of urbanizing rate is quite high in developing countries such as Nepal. The electricity use and the number of consumers increase at a rate of approximately $9 \%$ per year [18]. The average electricity use of the rural areas is $99 \mathrm{MJ} /$ household/month [19]. Fuelwood is the main source of energy in a rural household which is used for cooking, water boiling, and space heating, but the urban household has a cleaner source of energy whereas rural household consumes more traditional energy in Nepal [20-21].

The other research has given focused on firewood energy, gasses, fossil oil, and electricity in general. But this research has investigated the electricity use, family income, family size in rural, semi-urban, and urban households of Nepal. This research also analyses the actual amount of electricity use comparing with those patterns to rural, semi-urban, and urban households of Nepal.

\section{Methodology}

\subsection{The study areas}

The field study was conducted in Kalikot, Chitwan, and Kathmandu. Kalikot is a rural district which is in the western part of Nepal. Agriculture is the main occupation of its people. It has an altitude of 300 to $5,000 \mathrm{~m}$ and an area of $1,741 \mathrm{~km}^{2}$. The district consists of nine municipalities, out of which four are urban municipalities and five are rural municipalities with a population of 136,948 [22]. Chitwan is a semi-urban area that lies in the Terai region. It has an altitude of 300 to $2,000 \mathrm{~m}$ and an area of 2,238.39 $\mathrm{km}^{2}$. The district consists of 7 municipalities, out of which one is a Metropolitan city, five are urban municipalities and one is a rural municipality with a population of 579,984 . Kathmandu is the capital city of Nepal and its altitude up to $1,400 \mathrm{~m}$. The total population of Kathmandu metropolitan is 975,453 with 254,292 households (Figure 1). The houses were made of stone, wood, soil, straw, and zinc in rural area cement, bricks, iron, and zinc are used in urban areas (Figure 2). Those houses are not equipped, with any heating and cooling systems

\subsection{Data collecting procedure}

A quantitative research method was applied to this study. This study involved a socio-demography survey and household energy use, questionnaire, and observation of the household energy use patterns (Figure 3). The data were collected from 442 households in three regions in the winter season of 2018. The houses were randomly selected which was 114 household from the urban area, 112 from the semi-urban area and 216 from urban areas in Nepal. We have collected electricity bills, family income, and family size, electricity using appliances, expenditure for energy and energy use for heating/cooling, cooking, and lighting. The following household data have been collected: family size (above 10 years old only), qualification of respondents, income, hours of using electrical appliances, the numbers of appliances, onemonth electricity bills, firewood use per month ("Bhari" in local language) with price, sources of firewood, LPG cylinder (14.5 kg/cylinder). We also collected data on solar, candle, and kerosene use. The data also collected in terms of energy use for heating, cooking, and lighting with alternative energy sources. The electricity is generated by local micro-hydro in Kalikot which was not connected to the national grid but Chitwan and Kathmandu are connected to the national grid. The survey was conducted from $23^{\text {rd }}$ January to $21^{\text {st }}$ February 2018.

\section{Results and discussion}

\subsection{Electricity use situation of Nepal}

In Nepal, one of the least developed countries, around $302.4 \mathrm{PJ}(80.36 \%)$ out of $376.3 \mathrm{PJ}$ is used for the plants, $34 \%$ have been purchased from India and $23 \%$ are generated by diesel thermal power plants (Figure 4). The 


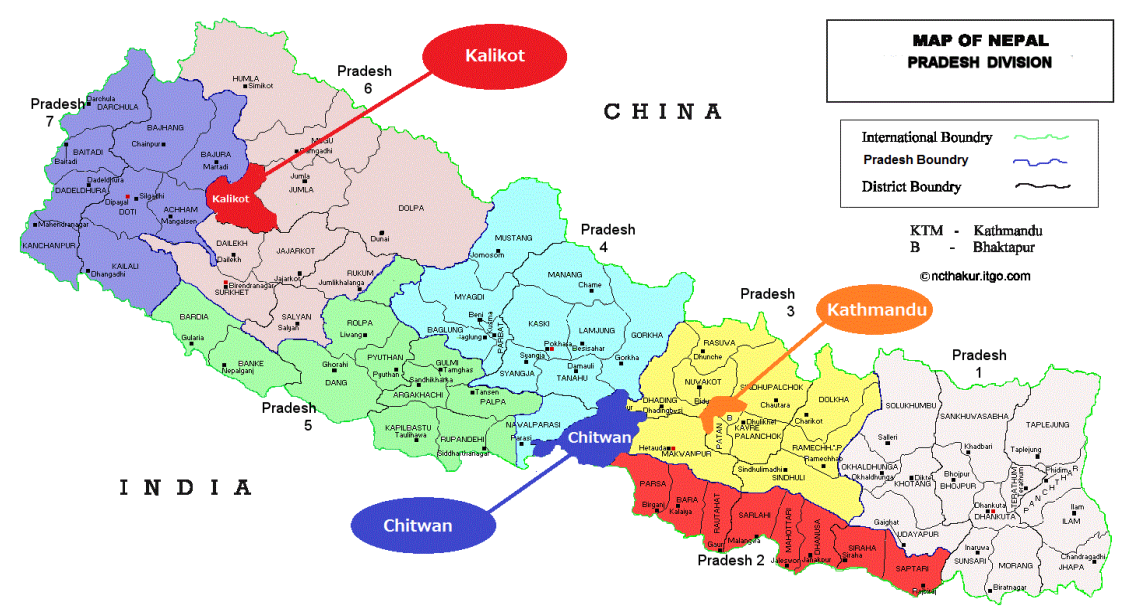

Figure 1: Map of Nepal
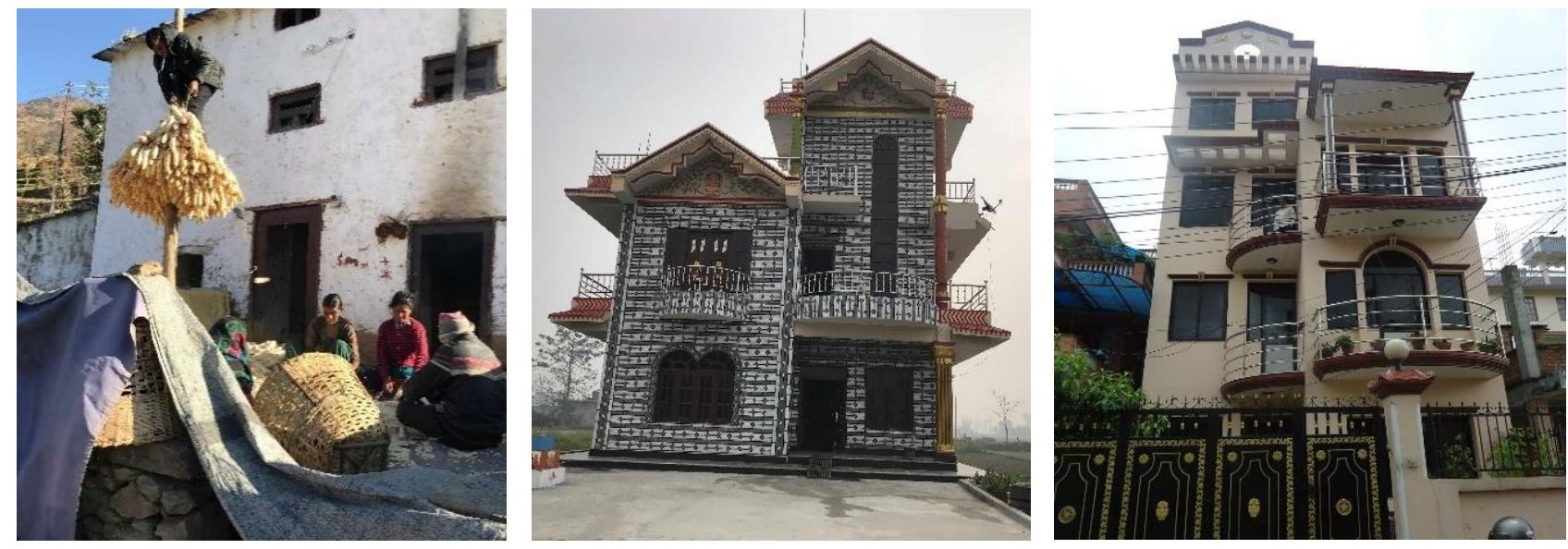

Figure 2: Houses of the study area (from left to right: Kalikot, Chitwan, Kathmandu)
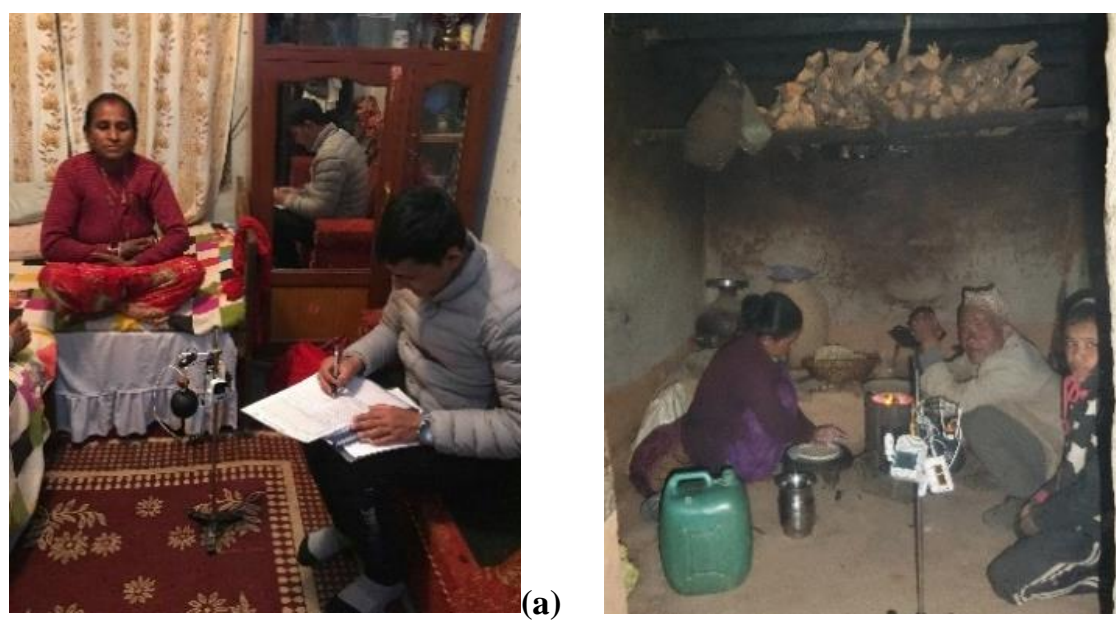

(b)

Figure 3: Data collection a) data collecting b) using firewood

residential sector. The electricity consumer's patterns in Nepal, $43 \%$ of electricity is generated by hydropower electricity consumer's patterns in Nepal are that $94 \%$ of use out of total electricity is in residential sectors. The availability of electricity was $11.27 \mathrm{TJ}$ in 2009 which has increased to $25.41 \mathrm{TJ}$ in 2018: 2.25 times larger than in
2009 (Figure 5) [18]. The household electricity users are more than those in industrial and commercial sectors due to low electricity production. Nepal has huge possibilities to produce the hydro energy sector than other developing countries because of the generation from hydropower on the run-of-the-rives from the Himalayas. The increased 


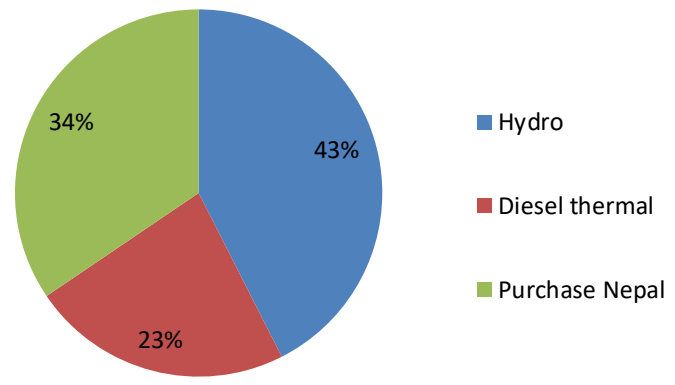

Figure 4: Electricity sources in Nepal

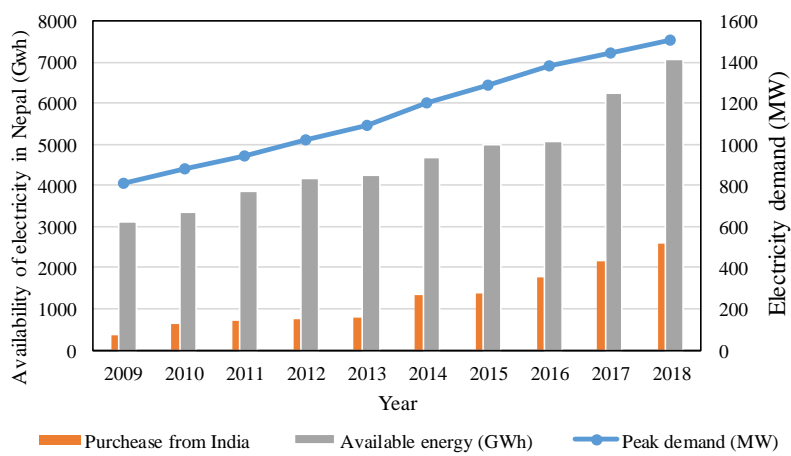

Figure 5: Electricity availability in Nepal

use of modern fuels such as electricity in Nepal has been possible because of the increased availability of electricity from several hydropower projects installed with financial and technical assistance from foreign countries such as India and China. The total installed capacity is 4,445 MW in Nepal (Table 1). Household demand has risen dramatically. Due to the continuously rising demand and stagnation in creating additional power generation capacities, a noticeable shortage of power supply since 2007 has been the consequence of cut power for up to 20 hours per day in some regions including urban centers in NEA 2009. But at the last year can be considered successfully achieved its primary goal of eradicating load shedding from the entire country from this year with the end to power cuts during peak hours in the industrial sector too. It might be the result of proper management, distribution, and awareness of saving energy in Nepal. Table 2 shows that the electricity tariff fixed by NEA [17]. They fixed two types charges such as service and energy charges which are categorized by phases. The minimum service charged fixed $20 \mathrm{NRs} / \mathrm{month}$ and $3 \mathrm{NRs/unit} \mathrm{up} \mathrm{to}$ 20 unit.

Table 1: Hydropower plant situation in Nepal

\begin{tabular}{lll}
\hline Stage & Category & $\begin{array}{l}\text { Installed } \\
\text { Capacity (MW) }\end{array}$ \\
\hline Completed & Hydropower Plants & 489 \\
$\begin{array}{l}\text { Under } \\
\text { Construction }\end{array}$ & Hydropower Plants & 1,017 \\
Planned & Hydropower Plants & 2,920 \\
Ongoing & Micro Hydropower Plants & 14 \\
Isolated & Micro Hydropower Plants & 5
\end{tabular}

Total

4,445

\subsection{Electricity use, GDP, and $\mathrm{CO}_{2}$ emission}

\subsubsection{Relationship between GDP and energy use}

The World Bank [2] recorded the electricity use and GDP of Nepal from 2006 to 2014. Figure 6 shows the

Table 2: Electricity tariff for domestic consumers in Nepal

\begin{tabular}{|c|c|c|c|c|c|c|c|c|c|}
\hline \multirow{2}{*}{\multicolumn{2}{|c|}{ kWh (Monthly) }} & \multicolumn{2}{|c|}{5 Ampare } & \multicolumn{2}{|c|}{15 Ampare } & \multicolumn{2}{|c|}{30 Ampare } & \multicolumn{2}{|c|}{60 Ampare } \\
\hline & & \begin{tabular}{|l|} 
Service \\
Charge
\end{tabular} & \begin{tabular}{|l|} 
Energy \\
Charge
\end{tabular} & $\begin{array}{l}\text { Service } \\
\text { Charge } \\
\end{array}$ & \begin{tabular}{|l|} 
Energy \\
Charge
\end{tabular} & \begin{tabular}{|l|} 
Service \\
Charge \\
\end{tabular} & $\begin{array}{l}\text { Energy } \\
\text { Charge }\end{array}$ & \begin{tabular}{|l|} 
Service \\
Charge
\end{tabular} & $\begin{array}{l}\text { Energy } \\
\text { Charge }\end{array}$ \\
\hline \multirow{7}{*}{ 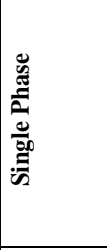 } & $0-20$ & 30 & 3 & 50 & 4 & 75 & 5 & 125 & 6 \\
\hline & 21-30 & 50 & 7 & 75 & 7 & 100 & 7 & 150 & 7 \\
\hline & 31-50 & 75 & 8.5 & 100 & 5.5 & 125 & 8.5 & 175 & 8.5 \\
\hline & 51-150 & 100 & 10 & 125 & 10 & 150 & 10 & 200 & 10 \\
\hline & 151-250 & 125 & 11 & 150 & 11 & 175 & 11 & 225 & 11 \\
\hline & 251-400 & 150 & 12 & 175 & 12 & 200 & 12 & 250 & 12 \\
\hline & Above 400 & 175 & 13 & 200 & 13 & 225 & 13 & 275 & 13 \\
\hline \multirow{4}{*}{ 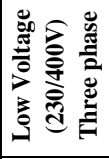 } & $\mathbf{r W h}$ & \multicolumn{4}{|c|}{ Up to $10 \mathrm{KVA}$} & \multicolumn{4}{|c|}{ Above 10 KVA } \\
\hline & chis & \multicolumn{2}{|c|}{ Service Charge } & \multicolumn{2}{|c|}{ Energy Charge } & \multicolumn{2}{|c|}{ Service Charge } & \multicolumn{2}{|c|}{ Enrgy Charge } \\
\hline & Up to 400 & \multirow{2}{*}{\multicolumn{2}{|c|}{1100}} & \multicolumn{2}{|l|}{12.5} & \multirow{2}{*}{\multicolumn{2}{|c|}{1800}} & \multicolumn{2}{|l|}{12.5} \\
\hline & Above 400 & & & \multicolumn{2}{|l|}{13.5} & & & \multicolumn{2}{|l|}{13.5} \\
\hline \multirow{5}{*}{ 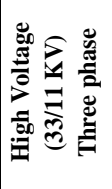 } & \multirow{2}{*}{\multicolumn{3}{|c|}{ kWh }} & \multicolumn{6}{|c|}{ Up to $10 \mathrm{KVA}$} \\
\hline & & & & \multicolumn{3}{|c|}{ Service Charge } & \multicolumn{3}{|c|}{ Energy Charge } \\
\hline & \multicolumn{3}{|l|}{ Up to 1000} & \multirow{3}{*}{\multicolumn{2}{|c|}{1100}} & & \multicolumn{3}{|l|}{11} \\
\hline & \multicolumn{3}{|l|}{ 1001-2000 } & & & & \multicolumn{3}{|l|}{12} \\
\hline & \multicolumn{3}{|l|}{ Above 2001} & & & & \multicolumn{3}{|l|}{12} \\
\hline
\end{tabular}


relationship between GDP per capita and electricity use. The total electricity use in Nepal (448 MJ/capita/year) is far smaller compared to the global (11.17 TJ/capita/year) electricity use rate and GDP per capita of Nepal (from 2006 to 2014). Kantar et al. [23] conducted a hierarchical structure of the countries based on electricity use and economic growth 64 countries on the based three-income group from 1971 to 2008 . They have been found different clusters of countries according to their geographical location and economic growth, a strong relationship between energy use and economic growth for all the income groups. They have given data in paper and we have plotted as shown in (Figure 7). We have excluded three countries (Iceland, Norway, and Luxemburg) because of different characteristics for GDP and electricity use. The electricity use and GDP were highly correlated. From the regression equation, we can estimate the relationship between them.

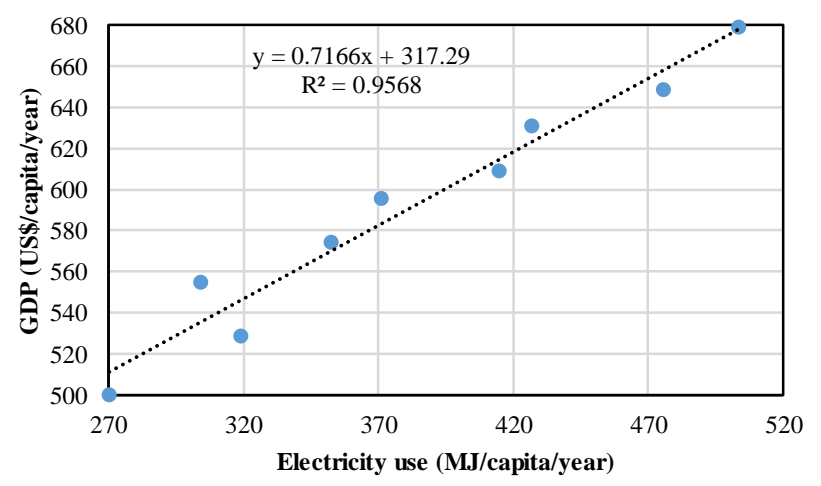

Figure 6: Electricity use and GDP per capita in Nepal

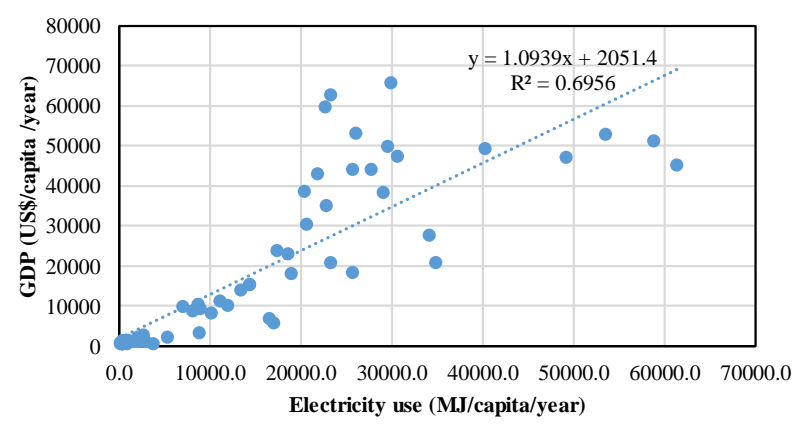

Figure 7: Electricity use and GDP per capita in the World

\subsubsection{Relationship between energy use and $\mathrm{CO}_{2}$ emission}

Chen et al. [24] conducted on the relationship between GDP and electricity use in 10 newly industrializing Asian countries in 2003. The total population of ten those countries was 2.8 billion, which accounts for $45 \%$ of the world's population. The GDP and electricity use in the region and US\$3572.71 billion and 3174.14 TWh (Terawatt per hour), which accounts for about $10.7 \%$ and $20.9 \%$ of the world's GDP and electricity use, respectively. Also, they found to be the combined $\mathrm{CO}_{2}$ emissions for those countries accounted for $25.1 \%$ of global emission in 2003, while China, India, and Korea were among the world's top 12 polluting countries in terms of $\mathrm{CO}_{2}$ emissions. Since in China, India, and Indonesia GDP per capita and electricity use per capita was so far below the world average. Those countries were account for a significant proportion of the world population, GDP, and electricity use. They have given data and we have plotted as shown in (Figs. 8 and 9). The electricity use and $\mathrm{CO}_{2}$ emission were highly correlated.

The equation can be used to estimate the relationship of them Wang et al. [25] also described China's composition of energy source is highly geographically dependent a large rural population still reside in areas where carbonate composites are a major energy source, consequently, the resulted carbon pollution has been an increasingly serious environmental problem.

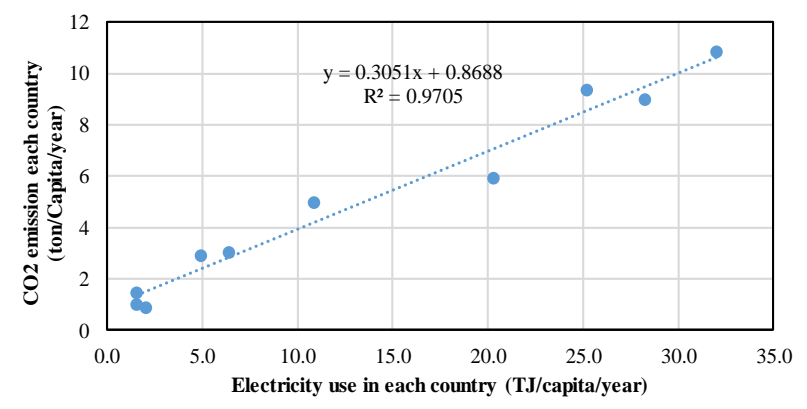

Figure 8: The relationship between electricity use and $\mathrm{CO}_{2}$ emission per capita per year

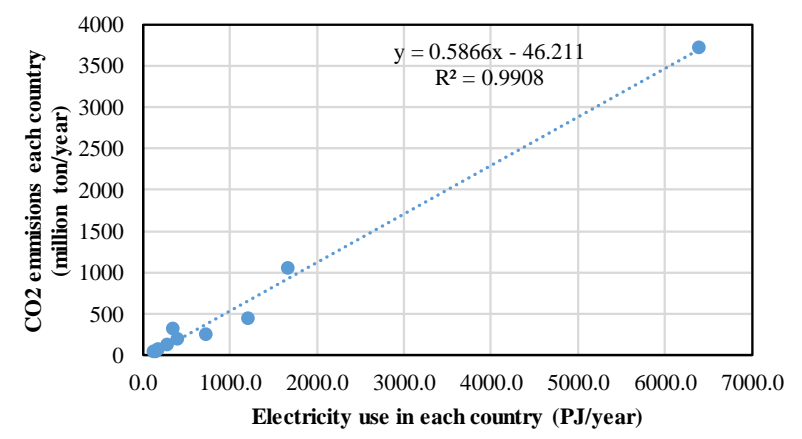

Figure 9: The relationship between electricity use and $\mathrm{CO}_{2}$ emission per country per year

\subsubsection{Household occupation, electricity use, and income}

The occupational groups were defined as business holders, job holders, and farmers. The monthly household's 
income and household electricity use were calculated according to the occupation. We have found the average household electricity use of $171.2 \mathrm{MJ} /$ household/month and the household mean expenditure for electricity 386 NRs/household/month with a total income of 29775 $\mathrm{NRs} /$ household/month which is $1.3 \%$ of household income. The business holder households had quite a higher income than other occupations in urban and semiurban areas but reverse in the rural areas. The farmer has used quite a low amount of electricity in urban and rural but reverses in semi-urban. If might be they have used a water pump and other farming appliances in semi-urban areas household. But business holder households have used higher electricity than others. It seems that electricity use not only affects income, but it affects the occupation and family size (Table 3 ). The average family size was found to be 3 people residing in the household in Nepal. The household size, occupant behavior, dwelling types are an important variable in determining residential electricity use.

\subsubsection{Income group, family size, and electricity use}

The income groups were defined in low, medium, and high based on the questionnaire's survey of total monthly income. The low-income group included all households with a monthly income $\leq 16666$ NRs. The high-income group was all households with a monthly income $\geq 36000$ NRs. The medium-income group lies between two categories. The results found that low-income group has few family members with high electricity use, the medium-income group has medium family size with medium electricity use and the high-income group has big family size with low electricity use per capita per months but vice-versa in household per month. It seems that income growth does not affect electricity use, but family size has effects on electricity use (Table 4). Similarly, electrical heater, computer, and iron are high in urban areas. Access to communication has rapidly increased in the last decade. But access to other electrical appliances is very low. It is due to the socio-economic condition of the people. Almost all houses visited were naturally ventilated. They adjust the thermal environment by traditional manners.

\subsubsection{Use of home electrical appliances}

Electric lamps and mobile phones have been used by $100 \%$ of households. TV, fan, refrigerator, and water pump are used in a high percentage in the semi-urban area.

Table 3: Income, family size, occupation, and energy use

\begin{tabular}{|c|c|c|c|c|c|c|c|c|}
\hline Study area & Occupation & Family size & $\begin{array}{l}\text { Income } \\
\text { (NRs/household/ } \\
\text { month) }\end{array}$ & $\begin{array}{l}\text { Income } \\
\text { (NRs/person/ } \\
\text { month) }\end{array}$ & $\begin{array}{l}\text { Electricity use } \\
\text { (MJ/household/ } \\
\text { month) }\end{array}$ & $\begin{array}{l}\text { Electricity use } \\
\text { (MJ/person/m } \\
\text { onth) }\end{array}$ & $\begin{array}{l}\text { Expanses for } \\
\text { electricity } \\
\text { (NRs/household/ } \\
\text { month }\end{array}$ & $\begin{array}{l}\text { Expanses for } \\
\text { electricity } \\
\text { (NRs/person/ } \\
\text { month }\end{array}$ \\
\hline \multirow{3}{*}{ Rural } & Job holder & 3 & 27164 & 9055 & 86.4 & 28.8 & 146 & 49 \\
\hline & Farmer & 4 & 8074 & 2019 & 64.8 & 18.0 & 95 & 24 \\
\hline & Business man & 4 & 13488 & 3372 & 90.0 & 21.6 & 167 & 42 \\
\hline \multirow{3}{*}{ Semi-urban } & Job holder & 4 & 37491 & 9373 & 140.4 & 36.0 & 306 & 77 \\
\hline & Farmer & 3 & 26093 & 8698 & 183.6 & 57.6 & 422 & 141 \\
\hline & Business man & 4 & 36960 & 9240 & 147.6 & 43.2 & 310 & 78 \\
\hline \multirow{3}{*}{ Urban } & Job holder & 3 & 36508 & 12169 & 302.4 & 100.8 & 753 & 251 \\
\hline & Farmer & 3 & 26783 & 8928 & 169.2 & 72.0 & 366 & 122 \\
\hline & Business man & 3 & 55417 & 18472 & 356.4 & 129.6 & 910 & 303 \\
\hline Average & & 3 & 29775 & 9036 & 171.2 & 56 & 386 & 121 \\
\hline
\end{tabular}

$1 \mathrm{US} \$=115.21 \mathrm{NRs}$

Table 4: Income group and energy use

\begin{tabular}{llll}
\hline Income group & $\begin{array}{l}\text { Average income } \\
(\mathrm{NRs} / \text { household/month })\end{array}$ & $\begin{array}{l}\text { Std. Deviation of income } \\
(\mathrm{NRs} / \text { household/month })\end{array}$ & $\begin{array}{l}\text { Average electricity use } \\
(\mathrm{MJ} / \text { household/month })\end{array}$ \\
\hline Low $(\leq 16666)$ & 9621 & 4264 & $\begin{array}{l}\text { Std. Deviation of electricity use } \\
(\mathrm{MJ} / \text { household/month })\end{array}$ \\
Medium $(17000-35000)$ & 25770 & 25515 & 189 \\
High $(36000 \geq)$ & 57860 & 22966 & 293 \\
\hline
\end{tabular}




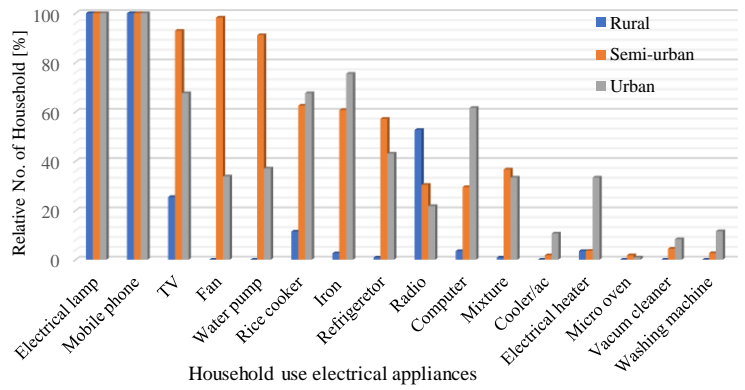

Figure 10: Relative number of households use electric appliances

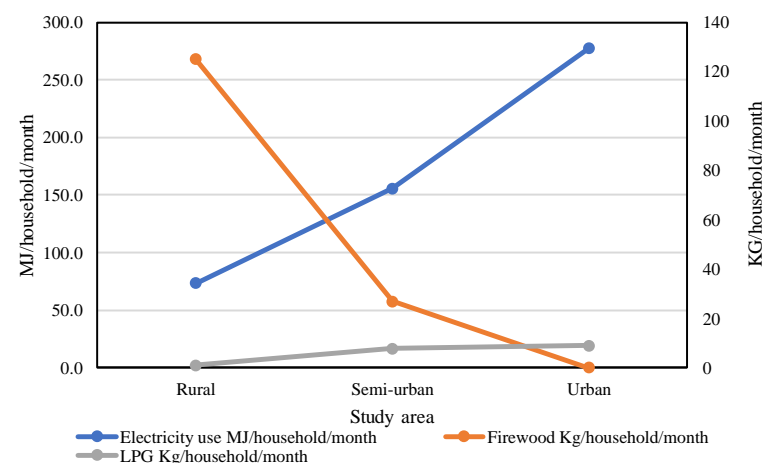

Figure 11: The electricity use in rural, semi-urban and urban area

\subsubsection{Energy use for cooking, heating, and lighting}

As shown in Figure 11, the amount of firewood used is 125 and $26.83 \mathrm{~kg} /$ household/month firewood is used for cooking and space heating in rural and semi-urban areas, respectively. This value lower than 235-1130 kg/capita/year obtained by Rijal and Yoshida [27]. The average LPG used is 9 and $7.74 \mathrm{~kg} /$ household/month in urban and semi-urban areas, respectively. The average number of electric bulbs was 5 with $18.25 \mathrm{~W}$ each. Generally, electricity is used for $5 \mathrm{hrs} /$ household/day. The total energy use for lighting is calculated as follows.

$$
\text { Energy use }[J]=\text { Power }[\mathrm{W} / \text { bulb }] \times \text { Time }[S]
$$

The total energy use for lighting was found to be 1642.5 $\mathrm{kJ} /$ household.

Almost all households used firewood and residual for cooking and space heating in rural areas. Electricity is used for lighting in three areas. LPG is available in semiurban and urban areas and it is mainly used for cooking purposes. Kerosene had been totally substituted by electricity and LPG (Figure 12). But some studies showed in developing countries, wood fuels do not disappear completely as incomes rise since many income households still use wood, reflecting the utility of these fuels for urban households. The firewood and residue were the main sources for cooking and heating purpose in rural areas. In rural areas of Bangladesh, they found that $95 \%$ of the households use biomass, $72 \%$ kerosene, $53 \%$ electricity, $23 \%$ LPG and $60 \%$ candle as fuel types. $87 \%$ of total energy is used by households in Nepal [26]. It is necessary to reduce the dependency on biomass for cooking and to promote domestic alternative energy sources. $76 \%$ depend on fuelwood for cooking; this implies that 20.22 million people depend on forests for their fuel needs.

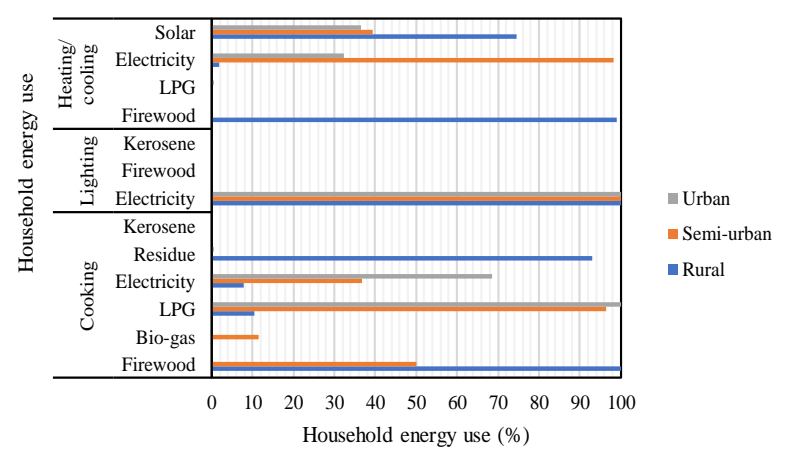

Figure 12: Energy use for cooking, lighting, and heating/cooling

\subsubsection{LED use and awareness}

Energy-saving is a serious concern in the world. It is not only concerned with saving money, but it also helps to preserve natural resources and the environment. Energy is mainly used for basic human needs and occupant comfort in the household. Household energy management and occupant behaviour are very important factors in energy. The building performance, equipment efficiency, and occupant behaviour play important roles in residential building for energy conservation [28]. In developing countries electricity is mainly used for lighting rather than other purposes. If we can reduce energy for lighting the cost will be reduced and it would support the saving energy. In recent years, LED lights are known for being more energy-efficient than CFLs and incandescent bulbs. According to multiple studies, LED lights use $75 \%$ less energy than incandescent and fluorescent bulbs whereas CFLs save around 20-35\% of energy. The fact is that LED lights are more environment-friendly, energy-saving, and long-lasting than fluorescent. As shown in Figure 13 while the level of education is increasing gradually the proportion of LED use is also increases significantly. It showed that awareness should be helpful for energy use for lighting purposes. 


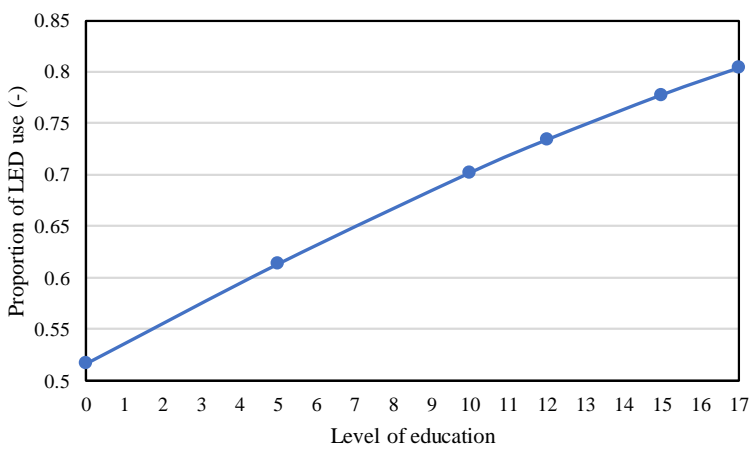

Figure 13: Education level and proportion of LED use

\section{Conclusions}

This study attempted to describe the electricity use in households through different variables. The electricity energy use of the rural areas of Nepal was investigated in 442 households with one months' electricity bills and income. The conclusions of this study are as follows:

1. The electricity was found to be 171.2 $\mathrm{MJ} /$ household/month and the household means electricity expenditure was 386 NRs/household/month of total income 29,775 NRs/household/month.

2. Firewood and residual were the main sources for cooking and heating in rural surveyed, but LPG and electricity are the main sources of energy for cooking in semi-urban and urban areas. Electricity was mainly used for lighting. The total energy use for lighting was $1642.5 \mathrm{~kJ} /$ household. Solar cells are used for lighting and water boiling purposes in rural and urban areas.

3. The use of electric lamps and mobile phones were $100 \%$ in the household, but access to other electrical appliances is very low.

4. Electricity use and GDP are highly correlated nationally and internationally.

5. The GDP and $\mathrm{CO}_{2}$ emission were highly correlated worldwide.

6. The proportion of LED used looks also affected by the education level of respondents.

\section{Acknowledgments}

We would like to thank all researchers whose data we have used, all the people who participated in the survey, especially like to give thanks to municipality officers, assistance, villagers, and Potmara micro-hydro officer.

\section{References}

[1] R. Wang and Z. Jiang, "Energy consumption in China's rural areas a study based on village energy survey", Journal of Cleaner Production, 143, pp. 452-461, 2017.

[2] World Bank, "Understanding poverty", 2013. http://www.worldbank.org/en/topic/energy. [Accessed Dec. 23, 2019].

[3] International Energy Outlook, "US energy information administration", 2017. https://www.eia.gov/outlooks/ieo/pdf/0484(2017).pdf. [Accessed Dec. 23, 2019].

[4] L. Chen, N. Heerink and M. Berg, "Energy consumption in rural china: A household model for three village in Jiangxi province", Ecological Economics, 58, pp. 407420, 2006

[5] S. Pachauri and L. Jiang, "The household energy transition in India and China", Energy Policy, 36, pp. 4022-4035, 2005.

[6] R. Heltberg, "Factors determining household fuel choice in Guatemala", Environment and Development Economics, 10, pp. 337-361, 2005.

[7] L. Zhang, Z. Yang, B. Chen and G. Chen, "Rural energy in China: Pattern and policy", Renewal Energy, 34, pp. 2813-2823, 2009.

[8] D.K. Shahi, H.B. Rijal, "Study on household electricity consumption in rural area of Nepal", SHASE Annual Conference IS-4, pp. 1-4, 2017.

[9] D.K. Shahi, H.B. Rijal and M. Shukuya, "A study on household energy-use patterns in rural, semi-urban and urban areas of Nepal based on field survey", Energy and Buildings 223 (2020) 110095.

[10] H.C. Petersen, "Electricity Consumption in Rural vs. Urban Areas", Western Journal of Agricultural Economics, 7, pp. 13-18, 1982.

[11] B. Sinha and I. Biswas, "Rural Energy Security in India: Reality Checks", India Science and Technology, pp. 1-5, 2009.

[12] M. Alam, J. Sathaye and D. Barnes, "Urban household energy use in India: efficiency and policy implications" Energy Policy, 26, pp. 885-891, 1998.

[13] V. Joon, A. Chandra and M. Bhattacharya, "Household energy consumption pattern and socio-cultural dimensions associated with it: A case study of rural Haryana, India" Biomass and Bioenergy, 33, pp. 1509-1512, 2009.

[14] S.R. Khandker, D.F. Barnes and H.A. Samad, "Energy poverty in rural and urban India: are the energy poor also income poor?", The World Bank, Policy research working paper WPS5463, 2010.

[15] D.B. Rahut, S. Das, G.D. Hugo \& B. Behera, "Determinants of household energy use in Bhutan" Energy, 69, pp. 661-672, 2014.

[16] WECS, Nepal, "Energy consumption situation in Nepal year 2011/2012", 2014.

[17] S. Malla, "Household energy consumption patterns and its environmental implications: Assessment of energy access and poverty in Nepal", Energy Policy, 61, pp. 990-1002, 2013.

[18] NEA, A Year in Review, 2017/2018. 
[19] B. Panthi \& N. Bhattarai, "Residential Sector Energy Demand and Analysis of Resunga Municipality, Gulmi, Nepal", Proceedings of IOE Graduate Conference, pp. 355-359, 2016.

[20] J. Shrestha, A. M. Nakarmi, "Residential Energy Consumption Pattern of a newly formed municipality: A case study of Bhojpur Municipality of Bhojpur District", IOE Graduate Conference, pp. 237-243, 2014.

[21] Y. Bajracharya and A.M. Nakarmi, "Current Energy Consumption in Bhaktapur District", IOE Graduate Conference, pp. 492-496, 2014.

[22] Central Bureau of Statistics, National Population and Housing Census, 2011.

[23] E. Kantar, A. Aslan, B. Deviren and M. Keskin, "Hierarchical structure of the countries based on electricity consumption and economic growth" Physica, 454, pp. 1-10, 2016.

[24] S.-T. Chen, H. I Kuo and C.-C. Chen "The relationship between GDP and electricity consumption in 10 Asian countries", Energy Policy, 35, pp. 2611-2621, 2007.

[25] R. Wang, Z. Jiang, "Energy consumption in China's rural areas: A study based on the village energy survey", Journal of Cleaner Production, 143, pp. 452-461, 2017.

[26] M. A. Foysal, M. L. Hossain, A. Rubaiyat, S. Sultana, M. K. Uddin, M. M. Sayem, J. Akhter, "Household Energy Consumption Pattern in Rural Areas of Bangladesh", Indian Journal of Energy, 1, pp. 2278-9278, 2012.

[27] H.B. Rijal and H. Yoshida, "Investment and evaluation of firewood consumption in traditional houses in Nepal", Indoor Air, pp. 1000-1005, 2002.

[28] S. Hu, D. Yan, S. Guo, Y. Cui and B. Dong, "A survey on energy consumption and energy usage behavior of households and residential building in urban", China Energy and buildings, 148, pp. 366-378, 2017. 